\title{
CALIBRAÇ̃̃O DO DISCO MEDIDOR DE PASTAGEM E ESTIMATIVA NUTRICIONAL POR ÁREA NA REGIÃO OESTE DE SANTA CATARINA
}

Originais recebidos em: 16/10/2011

Aceito para publicação em: 14/01/2012

Keliani Bordin

Universidade de São Paulo

keliani.bordin@yahoo.com.br

Gilmar Almeida Gomes

Universidade do Estado de Santa Catarina

x2gag@udesc.br

Weber Silva Robazzi

Universidade do Estado de Santa Catarina wrobazzi@yahoo.com.br

Erro! Fonte de referência não encontrada.

A alimentação do animal é um dos fatores determinantes na eficiência do manejo. $\mathrm{O}$ método de manejo Voisin dá ênfase no uso equilibrado dos recursos naturais com $\mathrm{o}$ objetivo de melhorar seu aproveitamento. Este trabalho investiga a estimativa de nutrientes em pastagens, obtida com dados da altura e densidade em sistemas de manejo Voisin. Os resultados mostram que as alturas da pastagem variam de 3,7 a $14,1 \mathrm{~cm}$ na propriedade 1 , e 6,88 a $16,56 \mathrm{~cm}$ na propriedade 2 . Nos entornos do piquete, as alturas da pastagem foram inferiores às encontradas no centro. A altura das pastagens variou de $3,21 \mathrm{~cm}$ a 25,59 $\mathrm{cm}$, tendo um aumento significativo nos meses de dezembro a abril. Uma estimativa realizada com pastagens de verão demonstra que cada $\mathrm{cm}$ de pastagem horizontal é composta por 327,43 g de Matéria Seca (MS), $159 \mathrm{~g}$ de Proteína Bruta (PB) e 5,89 g de Cálcio (Ca). Avaliando o sistema com pastagens de inverno, observou-se que, a cada $\mathrm{cm}$ de pastagem, foram encontradas em média 372,92 $\mathrm{g}$ de MS, $347,83 \mathrm{~g}$ de PB e $11,37 \mathrm{~g}$ de Ca. Com informações acerca da porção nutritiva destinada ao consumo, é possível obter um melhor controle e uma otimização do manejo animal.

Palavras-chave: Estimativa da massa de forragem. Método do disco. Composição nutricional.

\section{DISC METER CALIBRATION AND PASTURE NUTRITION ESTIMATE BY AREA IN WEST REGION OF SANTA CATARINA}

\begin{abstract}
The feeding of the animal is a determining factor in the efficiency of management. The management method Voisin gives emphasis on balanced use of natural resources in order to improve their utilization. This paper investigates the estimation of nutrients in pastures, with data obtained from the height and density in management systems Voisin. The results show that the heights of pasture varied from 3.7 to $14.1 \mathrm{~cm}$ in a property, and from 6.88 to $16.56 \mathrm{~cm}$ on the property. Environments in the paddock pasture heights were lower than those found in the center. The height of the pasture ranged from $3.21 \mathrm{~cm}$ to $25.59 \mathrm{~cm}$, with a significant increase in the months from December to April. An estimate done with summer pastures demonstrates that each of grazing $\mathrm{cm}$ horizontal consists of 327.43 g DM (dry matter), $159 \mathrm{~g}$ crude protein (CP) and $5.89 \mathrm{~g}$ of $\mathrm{Ca}$ (Calcium). Evaluating the system with winter pastures, it was observed that every inch of grass were found on average, $372.92 \mathrm{~g}$ of DM, CP and $347.83 \mathrm{~g}$ $11.37 \mathrm{~g}$ of $\mathrm{Ca}$ with nutritional information about the portion intended for consumption, it is possible to obtain a better control and optimization of livestock management.
\end{abstract}

Keywords: Estimation of forage mass. Disk method. Nutritional composition. 


\section{INTRODUÇÃO}

O Oeste de Santa Catarina caracteriza-se por ser uma região composta predominantemente por pequenas propriedades rurais. Apresenta uma população em torno de 1.077.901 habitantes, dos quais 43,73\% vivem no meio rural (SECRETARIA, 1997). Em 1998, cerca de 94\% das propriedades rurais possuíam área inferior a 50 hectares, sendo a pecuária uma de suas principais atividades econômicas (TESTA et al., 2003). Nos últimos anos, o setor da agricultura familiar tem passado por uma crise severa, a qual tem gerado um êxodo rural, sendo este um grande problema econômico da região (MELLO; SCHMIDT, 2003).

Uma das maneiras mais eficientes de obtermos produtividade, qualidade, baixo custo e sustentabilidade na produção com ruminantes é conhecermos e aperfeiçoarmos as técnicas do sistema de pastoreio. De acordo com Blaser et al. (1986), uma alta disponibilidade de forragem está diretamente relacionada com o desempenho animal, assim como a qualidade nutricional fornecida. O método de manejo descrito por Voisin utiliza um conjunto de fatores que buscam alcançar tempos corretos de ocupação e repouso das pastagens, assim como máxima ingestão de pastagem com qualidade pelos animais (SORIO, 2006).

O Brasil possui condições ambientais que proporcionam uma exploração de leite a pasto na maior parte do ano, constituindo a base da dieta dos ruminantes da grande maioria dos sistemas de produção na região. Segundo Holmes (1996), a pastagem é a fonte de nutrientes de valor mais baixo em sistema de alimentação, principalmente em países em desenvolvimento.

Inúmeros fatores afetam a qualidade das pastagens, segundo Van Soest (1994), o solo, o clima, o animal e doenças influenciam no crescimento e na composição das plantas forrageiras. A estimativa e o acompanhamento da variação da massa de forragem e sua composição nutricional é uma das formas mais efetivas de gerar subsídios para os diversos processos de gerenciamento e tomada de decisão sobre o manejo do pastejo (CUNHA, 2002).

Existe uma série de técnicas que nos permitem estimar a produção da massa forrageira de um pasto, desde métodos diretos de medição, que passam por cortes da amostra a ser avaliada, até métodos indiretos de medição que correlacionam outras medidas de maior facilidade de mensuração com a massa de forragem. De acordo com Cunha (2002), nos países de pecuária de manejo aprimorado, as técnicas de mensuração indireta de massa de forragem são bastante utilizadas pelos produtores e pesquisadores. Entretanto, no Brasil, devido ao grande número de espécies de plantas forrageiras utilizadas nas pastagens e a deficiência de 
conhecimentos sobre a fisiologia dessa plantas, a disponibilidade de técnicas de campo para esse tipo de estimativa é ainda incipiente.

De acordo com Pedreira (2001), é de extrema importância que se identifiquem as características da vegetação que estejam altamente correlacionadas com a massa de forragem e que possam ser medidas rápida e facilmente. Isso pode ser feito com o disco medidor de pasto. Trata-se de um instrumento simples, que pode ser facilmente incluído no cotidiano dos proprietários, contribuindo para um conhecimento mais amplo e controle sobre sua produção, o que aumenta a eficiência do seu processo produtivo.

Para Frame (1981), o método do quadrado é altamente confiável desde que os locais de amostragem sejam definidos segundo a casualização. Pedreira (2001) considera que cada área cortada representa uma fração muito pequena da vegetação, e isso pode induzir a erro no momento de se estimar a massa de forragem total da área.

Assim, a pecuária baseada em alimentação com pastagem é uma alternativa economicamente viável em regiões onde as condições ambientais proporcionam uma produção com baixo custo na maior parte do ano, tornando a produção de leite a pasto uma das atividades mais competitivas sobre o uso da terra.

O objetivo deste trabalho foi fazer a calibração do disco medidor de pastagem e estimar a composição nutricional com dados encontrados na literatura.

\section{MATERIAIS E MÉTODOS}

O experimento foi realizado no município de Pinhalzinho, cujo clima é subtropical e o tipo de solo é argiloso, e as amostras foram analisadas no Laboratório de Química Inorgânica, Orgânica e Físico-Química da Universidade do Estado de Santa Catarina.

Foram selecionadas duas pequenas propriedades rurais de Pinhalzinho (propriedades 1 e 2), nas quais utilizam-se policultura e mão de obra familiar. O método de manejo utilizado nas propriedades avaliadas é o método Voisin, implementado há mais de quatro anos nas propriedades.

A área de pastagem das propriedades varia de 5 a 8 hectares, e a dos piquetes varia de 600 a $625 \mathrm{~m}^{2}$. O relevo das duas propriedades é semelhante, com pouco pedregulho e levemente sinuoso.

As coletas foram realizadas no piquete onde imediatamente o animal seria encaminhado ao pastejo. Quanto ao índice pluviométrico e à umidade relativa, como padrão, 
foram coletadas as amostras no mínimo dois dias após ter chovido e no período vespertino, entre 14 e 16h30. As forragens foram acomodadas em sacolas plásticas herméticas e imediatamente encaminhadas ao laboratório.

\subsection{Método do quadrado}

As amostras foram coletadas no período de agosto de 2007 a julho de 2008, sendo compostas de cinco subamostragens por amostra realizada. As amostras foram obtidas atirando-se aleatoriamente no piquete uma armação de ferro em forma de quadrado com lados de $30 \mathrm{~cm}$ x $30 \mathrm{~cm}$, resultando em uma área de $900 \mathrm{~cm}^{2}$ a cada subamostragem realizada. Com uma foice de uso agrícola, a pastagem foi coletada e acomodada em sacolas plásticas, as quais foram encaminhadas imediatamente ao laboratório. Para altura do corte, utilizou-se, como padrão, em torno de $7 \mathrm{~cm}$.

As coletas foram realizadas a cada 30 dias aproximadamente, respeitando o período mínimo de três dias após alterações no índice pluviométrico.

As amostras de cada subamostragem foram homogeneizadas, e então foi medida a massa total de pastagem. Do total da amostragem de pasto, apenas uma amostra foi analisada, sendo separada pelo método do quarteamento. As espécies foram separadas visualmente, e a massa individual de cada espécie foi quantificada, assim como a dos resíduos (pasto seco ou galhos) coletados juntamente com a amostra.

A avaliação da matéria úmida e seca foi realizada segundo Silva e Queiroz (2002), sendo realizada por método de secagem em estufa e pesada com balança semianalítica da marca Marte, modelo AL500.

\subsection{Método do disco}

O método do disco medidor é um método indireto utilizado em medições e estimativas de massa de forragem. Basicamente consiste em uma haste graduada na qual corre um prato (plástico acrílico) que, colocado ou solto na vegetação, registra a altura de repouso (Figura 1). 
Figura 1- Disco Medidor (esquema).
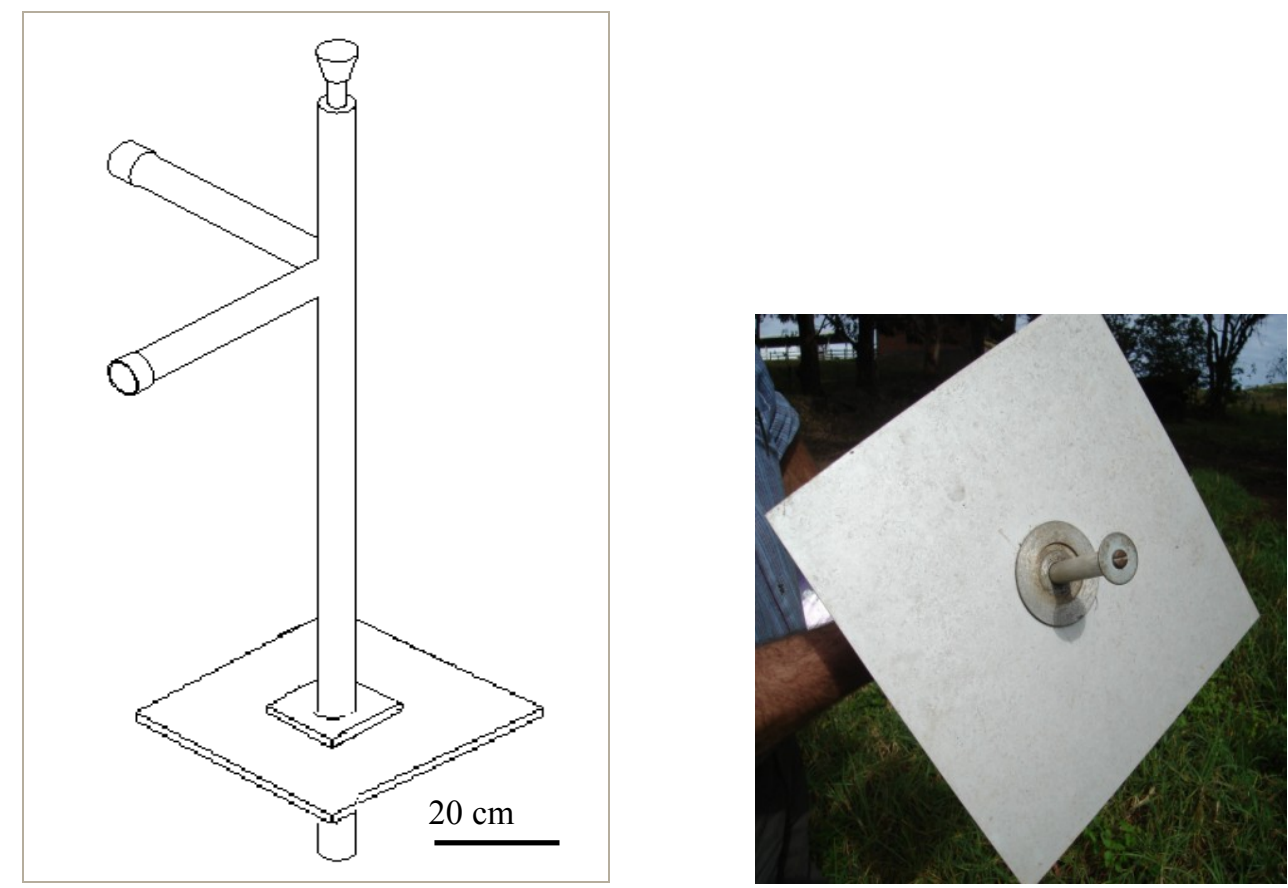

Em cada piquete foram coletadas as subamostragens pelo método do quadrado. No mesmo piquete, foram feitas 31 medições com o disco medidor, dispostas segundo a Figura 2.

Figura 2- Disposição dos pontos avaliados com o disco medidor de pasto.

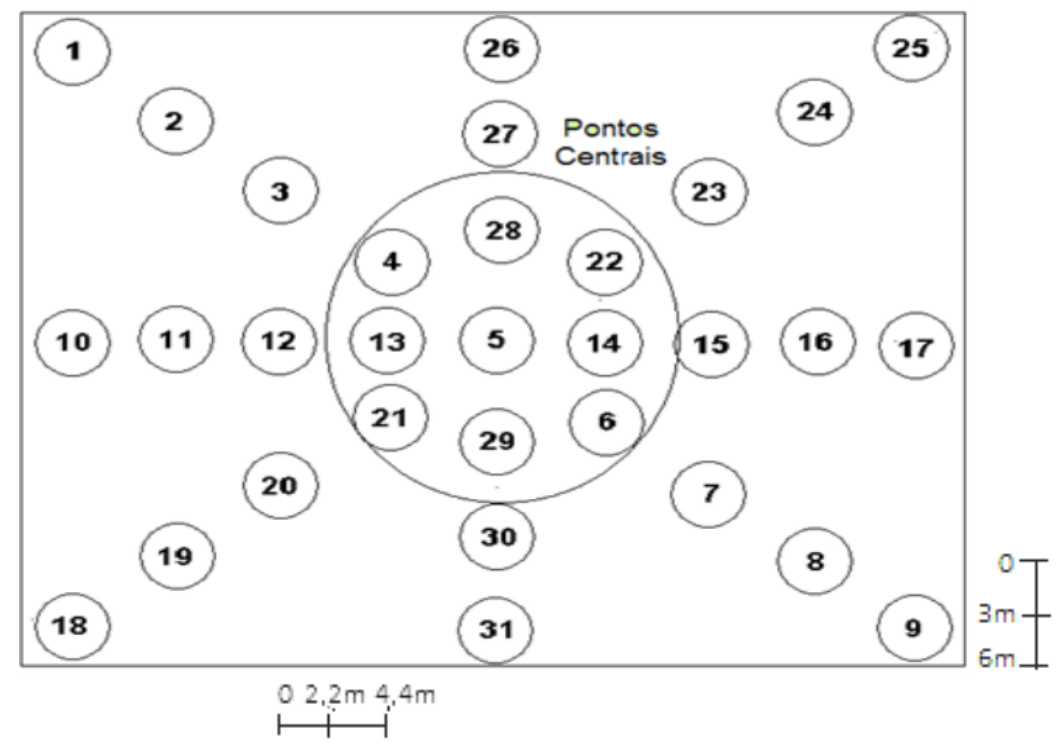

\subsection{Calibração}

Através da densidade calculada com a massa de forragem, conseguimos estimar a massa total por unidade de área. Com isso, relacionamos as medidas da altura total com a massa, como método de calibração do disco.

Extensio: R. Eletr. de Extensão, ISSN 1807-0221 Florianópolis, Ano 8, n. 12, p. 122-132, 2011. 
Para a padronização do disco, foi inicialmente calculada a densidade superficial da amostra, a qual é dada pela Equação 1:

$$
\sigma=\frac{M}{A}
$$

onde:

$\sigma=$ densidade

$M=$ massa

$A=$ área

Utilizando a densidade encontrada através do quadrado, é possível calcular a massa aproximada de pastagem, $M$, num piquete de área igual a $625 \mathrm{~m}^{2}$, através da equação (Eq. 2) da densidade já mencionada:

$$
M=\sigma A
$$

A partir disso, é possível relacionar a altura total medida pelo disco com a massa calculada e obter a relação entre altura e a massa para calibração do disco. Com isso, obtevese a relação entre a altura comprimida pelo disco e a massa de pastagem no piquete, conforme pode ser visto abaixo:

$$
\begin{aligned}
& \Sigma \text { alturas (cm)...........M (g) } \\
& 1 \mathrm{~cm} \ldots \ldots \ldots \ldots \ldots \ldots \ldots . . . . . . . . . . .(g)
\end{aligned}
$$

Onde:

$\Sigma$ alturas $=$ somatória das alturas dos pontos analisados através do disco

Com esses dados, conseguimos estimar a massa de forragem por $\mathrm{cm}$ de pastagem horizontal.

\section{RESULTADOS E ANÁLISE}

Na Figura 3 são apresentadas as médias das alturas encontradas nos pontos analisados nos piquetes. 
Figura 3- Altura média dos pontos analisados

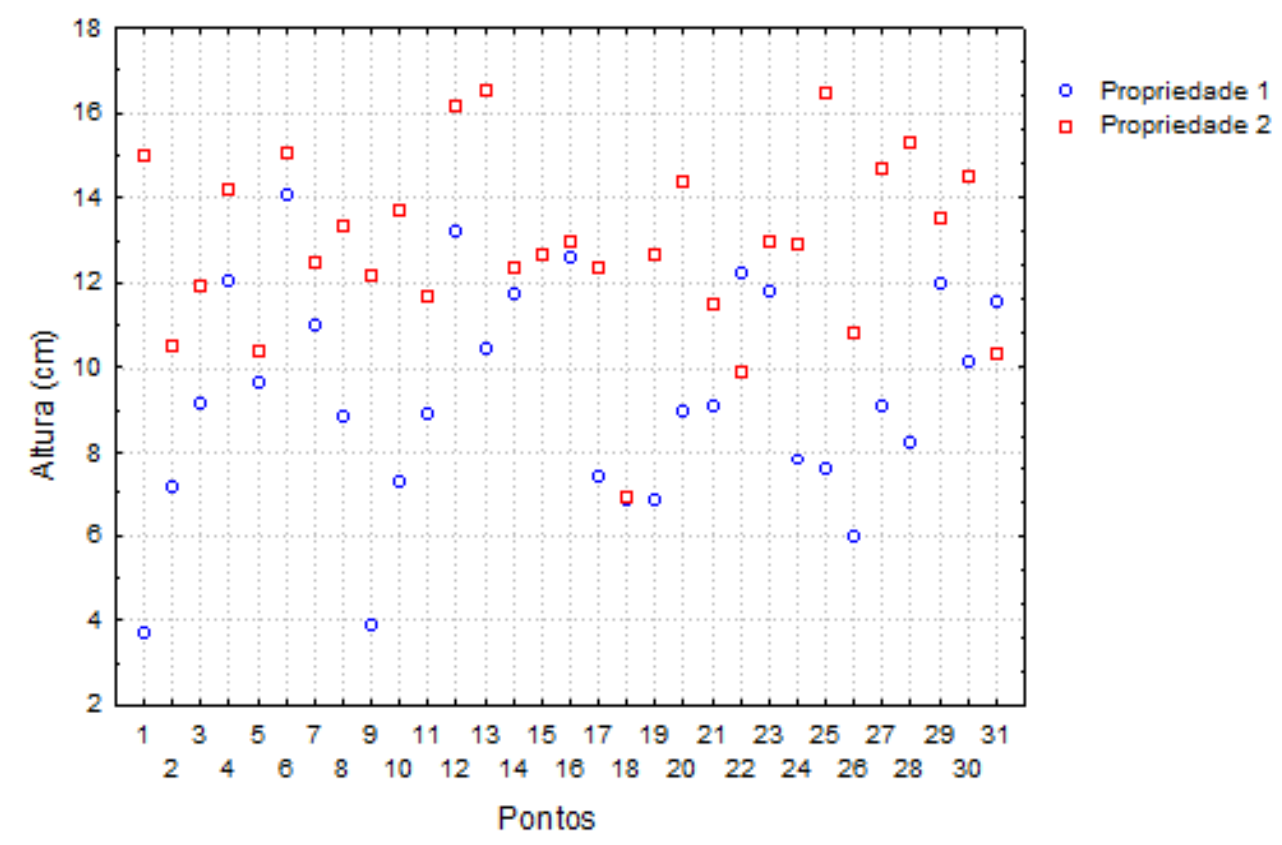

A medida de altura das pastagens não demonstrou comportamento linear, entretanto, podemos observar uma tendência de comportamento, verificado na Figura 3. Na Propriedade 1 , os valores variam de 3,7 a $14,1 \mathrm{~cm}$, com valores mais elevados localizados próximos ao centro do piquete. Na Propriedade 2, os valores variam de 6,88 a 16,56 cm, corroborando com os dados da Propriedade 1, onde os pontos centrais apresentam maiores alturas. O comportamento dos animais nos piquetes reflete nesse pisoteio nas extremidades e, consequentemente, há dificuldade de crescimento das pastagens nesses locais. Além disso, o relevo acidentado da propriedade e outros interferentes (como pedregulhos) podem afetar os resultados, gerando um erro experimental inevitável, decorrente do perfil das propriedades localizadas na região.

A Propriedade 1 apresentou menores alturas, provavelmente devido a algumas variações no manejo, como a adubação e tempo de permanência dos animais no piquete.

No estudo realizado por Piazzeta (2007), foram avaliadas que as diferentes alturas de pastejo interferiam na produtividade animal. Foi demonstrado que a altura da pastagem (aveia e azevém) próximo a $7 \mathrm{~cm}$ ou $28 \mathrm{~cm}$ apresenta baixos ganhos por área. Os tratamentos utilizados com altura média de $14 \mathrm{~cm}$ e $21 \mathrm{~cm}$ apresentaram ganhos de peso por área satisfatórios, sendo semelhantes aos obtidos por Silva et al. (2004) e Macari et al. (2006). Os resultados apresentados no trabalho em tela estão de acordo com esses dados, principalmente na Propriedade 2, demonstrando uma eficiência no manejo. 
No Quadro 1, são demonstrados os resultados das alturas obtidas com o método do disco medidor de pastagem, comparados com a massa estimada com o método do quadrado e, então, relacionados com a densidade.

Quadro 1. Resultados obtidos com o disco medidor de pastagem, e a massa obtida através do método do quadrado

\begin{tabular}{|c|c|c|c|c|}
\hline \multicolumn{5}{|c|}{ PROPRIEDADE 1 } \\
\hline Mês & Altura média (cm) & $\boldsymbol{\Sigma}$ alturas (cm) & $\boldsymbol{\sigma}$ (g/cm2) & Massa/Horizontal (g/cml) \\
\hline Ago/07 & 3,21 & 93,20 & 0,07 & 4627,14 \\
\hline Dez/07 & 14,53 & 450,30 & 0,04 & 652,34 \\
\hline Fev/08 & 7,21 & 223,60 & 0,07 & 2152,28 \\
\hline Mar/08 & 18,31 & 567,55 & 0,10 & 1114,63 \\
\hline Abr/08 & 10,29 & 319,00 & 0,07 & 1442,00 \\
\hline Jun/08 & 7,28 & 225,60 & 0,05 & 141,73 \\
\hline Jul/08 & 5,02 & 155,70 & 0,03 & 1324,66 \\
\hline Média & 9,41 & 290,71 & 0,06 & 1137,04 \\
\hline & & PROPRIEDADE 2 & Massa/Horizontal (g/cm) \\
\hline Mês & Altura média (cm) & $\mathbf{\Sigma}$ alturas (cm) & $\mathbf{\sigma}$ (g/cm2) & 2987,83 \\
\hline Jul/07 & 8,22 & 230,10 & 0,11 & 4957,23 \\
\hline Ago/07 & 4,59 & 128,60 & 0,10 & 1347,32 \\
\hline Fev/08 & 25,59 & 742,10 & 0,16 & 858,93 \\
\hline Mai/08 & 19,95 & 618,50 & 0,08 & 2936,74 \\
\hline Jul/08 & 5,55 & 166,00 & 0,08 & 2617,61 \\
\hline Média & 12,78 & 377,06 & 0,11 & \\
\hline
\end{tabular}

Fonte: Elaborado pelos autores

Avaliando os períodos estudados, a altura da pastagem na Propriedade 2 variou de $3,21 \mathrm{~cm}$ no mês de agosto a 25,59 cm no mês de fevereiro, tendo um acréscimo nos meses de dezembro a abril.

A altura da forragem e, consequentemente, o somatório das alturas sofreram significativas variações ao longo do ano (Quadro 1). O crescimento das pastagens pode sofrer variações decorrentes de diversos fatores, como condições climáticas, adubação e tempo de permanência dos animais.

Durante o período de calor (verão), existe elevada disponibilidade de fatores climáticos e edáficos de crescimento, e as plantas encontram-se normalmente em pleno crescimento vegetativo. Nos períodos mais frios, muitas vezes a decapitação de meristemas 
reprodutivos resulta em morte e, consequentemente, na redução da velocidade de crescimento das plantas (LIMÃO, 2010).

A densidade das pastagens analisadas na Propriedade 1 apresentou uma média de 0,06 $\pm 0,04 \mathrm{~g} / \mathrm{cm}^{2}$ e, na Propriedade 2, uma média de $0,11 \pm 0,05 \mathrm{~g} / \mathrm{cm}^{2}$, não obtendo um comportamento linear ao longo dos meses. Fatores como a espécie de pastagem e o tempo de crescimento podem influenciar na densidade da pastagem, além das condições externas às quais é submetida.

A massa de pastagem por $\mathrm{cm}$ horizontal é influenciada por fatores climáticos e propriedades dos solos, por isso, os valores têm uma variação anual muito elevada. A estimativa de massa de pastagem por $\mathrm{cm}$ horizontal na Propriedade 1 foi de 1137,04 \pm 995,31 g/cm horiz. e, na Propriedade 2, obteve uma média de 2617,61 $\pm 4098,3$ g/cm horiz. Os valores apresentados de massa de forragem por altura não foram lineares com a altura da pastagem, devido às variações na densidade.

A estimativa da massa de forragem em propriedades rurais consiste em uma ferramenta importante para o manejo adequado de forrageiras em sistema de exploração de pecuária baseado no uso de pastagem. Com base na massa coletada e uma estimativa visual das principais espécies na região, foram avaliadas as proporções das espécies de pastagem nos piquetes e comparados com os valores obtidos no estudo de Bordin et al. (2008) avaliando o conteúdo nutricional de pastagens na mesma região, em diferentes épocas do ano (Quadro 2).

Quadro 2. Composição média das principais espécies utilizadas

\begin{tabular}{|c|c|c|c|}
\hline Espécie & MS\% & $\mathbf{N \%}$ & $\mathbf{C a} \%$ \\
\hline Tifton & 24,43 & 1,90 & 0,44 \\
\hline Azevém & 18,36 & 2,74 & 0,56 \\
\hline Trevo branco & 14,74 & 3,56 & 0,55 \\
\hline Aveia & 18,64 & 2,45 & 0,52 \\
\hline
\end{tabular}

Fonte: BORDIN et al., (2008)

A partir dos dados apresentados por Bordin et al. (2008), feitos na mesma região, foram estimadas as porções de alguns nutrientes a partir de algumas espécies de pastagens. A Propriedade 1 foi utilizada com base no estudo por ser avaliada em um maior período. Analisando algumas das principais espécies utilizadas na região, temos a estimativa nutricional em diferentes períodos. Em períodos mais quentes, com alimentação baseada em Extensio: R. Eletr. de Extensão, ISSN 1807-0221 Florianópolis, Ano 8, n. 12, p. 122-132, 2011. 
tifton e aveia, podemos estimar que, a cada cm de horizontal, a pastagem possui 327,43 g de matéria seca, $159 \mathrm{~g}$ de proteína bruta e 5,89 g de cálcio. Em períodos mais frios, em que a alimentação é baseada em pastagens de inverno como azevém e trevo branco, pode-se estimar que cada cm de pastagem é composta por 372,92g de matéria seca, 347,83 g de proteína bruta e 11,37 g de cálcio. As pastagens utilizadas em períodos mais frios, como azevém e trevo branco, apresentaram maior teor de nutrientes, devido à composição nutricional das espécies.

\section{CONSIDERAÇÕES FINAIS}

Com os resultados obtidos, demonstrou-se que os pontos centrais dos piquetes analisados apresentam maiores alturas de pastagens, devido principalmente ao comportamento animal.

A estimativa de massa horizontal de pastagem não seguiu um comportamento linear, entretanto, a altura das pastagens foi inferior nos meses mais frios, corroborando com dados da literatura. No período em que se utilizam pastagens de inverno, a qualidade do pasto é superior a do verão, devido à qualidade nutricional das espécies nesse período.

Os resultados demonstram que é possível fazer uma estimativa da proporção de nutrientes de forma simplificada. Dessa maneira, é possível que o produtor tenha um maior controle sobre sua produção, podendo interferir no seu processo e obter um maior rendimento de maneira simplificada.

\section{REFERÊNCIAS}

BLASER, R.E., RHAMM, R.C., FONTENOT, J.P. Forage animal management systems. Virginia, USA, 1986, 96 p.

BORDIN,K., MIGLIORANZA, S.M., GOMES, G.A. Produção de leite e a interferência da capacidade nutricional das pastagens no método Voisin. In.: Congresso.México. Anais, 2008.

CUNHA, W.F. Métodos indiretos para estimativa de massa de forrgem em pastagens de Cynodon spp. 2002. (Dissertação Mestrado). Escola Superior de Agricultura Luiz de Queiroz. Piracicaba.

FRAME, J. Herbage mass. In: HODGSON,J.; BAKER, R.D; DAVIES, A.; LAIDLAW, A.S.; LEAVER, J.D. (Ed.) Sward mensurament handbook. Berkshire. Cap. 3, p. 39-67, 1981.

HOLMES, C. W. Produção de leite a baixo custo em pastagens: uma análise do sistema neozelandês. In: CONGRESSO BRASILEIRO DE GADO LEITEIRO, 2, 1995, Piracicaba. Anais. Piracicaba: FEALQ, p.69-95, 1996. 
KENNEDY, et al. Effect of herbage allowance and concentrate supplementation on dry matter intake, milk production and energy balance of early lactating dairy cows. Livestock Science, n.117, p. 275-286, 2008.

LIMÃO, V.A. Padrões de crescimento de pastos de capim-mulato submetidos a estratégias de pastejo rotativo. 2010, (Dissertação Mestrado), Universidade de São Paulo, Piracicaba.

MACARI, S.; ROCHA, M. G.; RESTLE, J.; PILAU, A.; FREITAS, F. K.; NEVES, F. P. Avaliação da mistura de cultivares de aveia preta (Avena strigosa Schreb) com azevém (Lolium multiflorum Lam.) sob pastejo. Ciência Rural. 2006, v.36, n.3, p.910-915.

MARTZ, F,A., et.al. Nutrient Content Dry Matter Yield and Species Composition of CoolSeason Pasture with Management-Intensive Grazing. Journal of Dairy Science. 1999, v. 82, n.7., 1538-1544.

MELLO, M.A.; SCHIMIDT, W. A agricultura familiar e a cadeia produtiva do leite no Oeste catarinense: possibilidade para a construção de modelos heterogêneos. In:

Agricultura e espaço rural em Santa Catarina, Editora da UFSC, Florianópolis, 311p. 2003.

PEDREIRA, C.G.S. Avanços metodológicos na a avaliação de pastagens. In: Reunião Anula da Sociedade Brasileira de Zootecnia, 39. Recife, 2001. Anais. Recife:SBZ, p. 100150.

PIAZETTA, R.G., Produção e comportamento animal em pastagem de aveia e Azevém, submetida a diferentes alturas de manejo. 2007. (Dissertação Mestrado). Universidade Federal do Paraná, Curitiba,.

Secretaria de Estado do Desenvolvimento Urbano e Meio Ambiente. Bacias hidrográficas do estado de Santa Catarina: diagnóstico geral. Governo do Estado de SC: Florianópolis, $1997,163 \mathrm{p}$.

SILVA, A.C.F.; QUADROS, F.L.F.; TREVISAN, N.B. Recria de terneiros de corte em pastagem de estação fria sob níveis de biomassa de folhas verdes: economicidade e eficiência alimentar. Ciência Rural, 2004, v.34, n.6, p.1903-1907.

SILVA, D.J.; QUEIROZ, A.C.; Análise de Alimentos: métodos químicos e biológicos. 3. ed. Viçosa: UFV, 2002.

SORIO,H. Pastoreio Voisin: teorias-práticas-vivências, Passo Fundo, 2ed, 2006.

TESTA, V.M.; MELLO, M.A.; FERRARI, D.L.; SILVESTRO, M.L.; DORIGON,C. A escolha da trajetória da produção de leite como estratégia de desenvolvimento do Oeste Catarinense, 2003. $130 \mathrm{p}$.

VAN SOEST, P.J. Nutritional ecology of the ruminant. 1994. 2.ed. Ithaca: Cornell University Press, 1994, 476 p. 